\title{
Outcomes in Patients Implanted With a Watchman Device in Relation to Choice of Anticoagulation and Indication for Implant
}

\author{
Muhammad Ajmal ${ }^{1}$, Mathew Hutchinson ${ }^{2}, \mathrm{Kwan} \mathrm{Lee}^{1}$, and Julia Indik ${ }^{1}$ \\ ${ }^{1}$ The University of Arizona College of Medicine Tucson \\ ${ }^{2}$ University of Arizona College of Medicine
}

October 19, 2020

\begin{abstract}
Background Patients with atrial fibrillation are increasingly prescribed a direct oral anticoagulant (DOAC) over warfarin and seek to avoid anticoagulation even without a history of major bleeding. This study explores the outcomes of patients implanted with a Watchman device in relation to anticoagulation choice (warfarin versus DOAC) in the post-procedure period and a history of bleeding. Methods Patients implanted with a Watchman device at a single center were retrospectively analyzed. Characteristics including anticoagulation in the first 45 days and history of major bleed were assessed and efficacy (thromboembolism) and safety (bleeding) outcomes compared by Kaplan-Meier analysis. Results 209 patients were implanted (57\% male, age $74.6 ? 7.8$ years) and followed for $23.5 \pm 7.1$ months. In the first half of patients, $98 \%$ were prescribed warfarin, which dropped to $51 \%$ in the second half $(\mathrm{p}<0.0001)$. A history of major bleed was present in $80.8 \%$ of the first half of patients and decreased to $60 \%$ in the second half $(\mathrm{p}=0.001)$. There were 16 safety and 4 efficacy events. There was no difference in safety outcomes according to history of major bleeding or anticoagulant choice in the first 45 days. There was no difference in efficacy outcomes over the duration of follow up according to anticoagulation choice in the first 45 days. Conclusions Patients implanted with a Watchman device were increasingly over time prescribed a DOAC and implanted without a history of major bleeding. Bleeding and thromboembolic events were infrequent and related neither to choice of anticoagulant nor to prior major bleeding.
\end{abstract}

\section{Hosted file}

Outcomes after Watchman - Ajmal et al.pdf available at https://authorea.com/users/368471/ articles/487588-outcomes-in-patients-implanted-with-a-watchman-device-in-relation-tochoice-of-anticoagulation-and-indication-for-implant

\section{Hosted file}

Table 1.pdf available at https://authorea.com/users/368471/articles/487588-outcomes-inpatients-implanted-with-a-watchman-device-in-relation-to-choice-of-anticoagulation-andindication-for-implant 

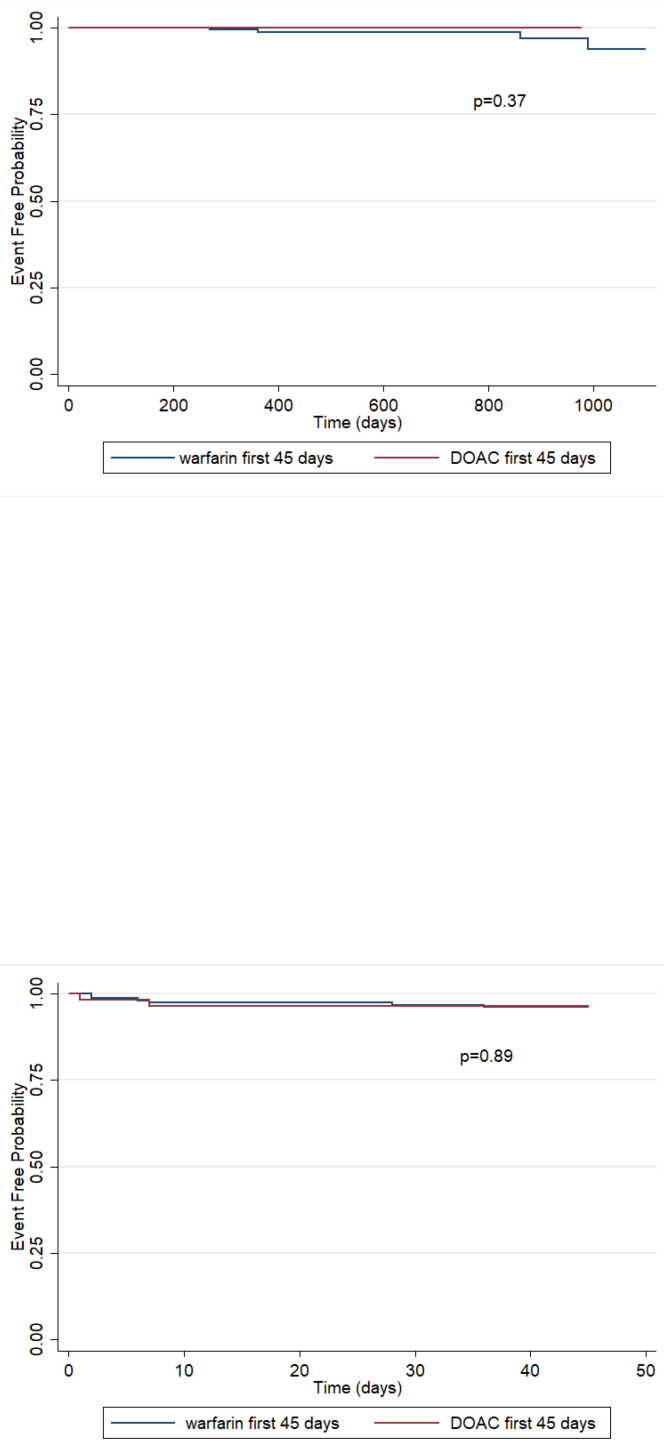


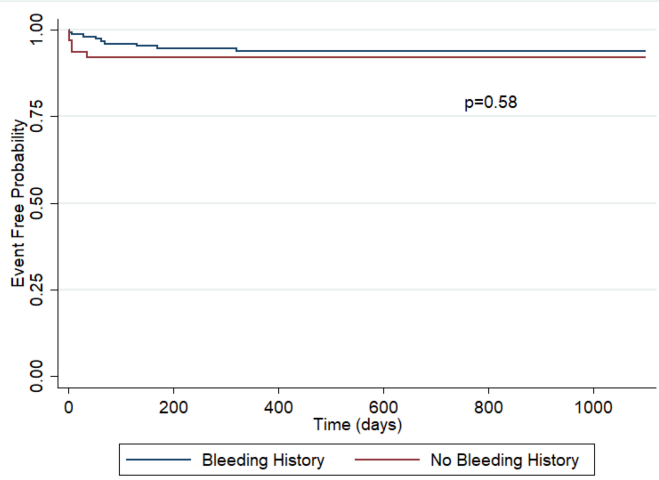

